\title{
THE IMPACT OF LASER PROCESSING ON THE PERFORMANCE PROPERTIES OF ELECTRO-SPARK COATINGS
}

\author{
N. RADEK ${ }^{1}$, R. DWORNICKA ${ }^{2}$ AND D. GONTARSKI ${ }^{3}$ \\ ${ }^{1}$ Kielce University of Technology, Faculty of Mechatronics and Mechanical Engineering, \\ Al. 1000-lecia Panstwa Polskiego 7, PL-25314 Kielce, Poland \\ norrad@tu.kielce.pl \\ ${ }^{2}$ Cracow University of Technology, Faculty of Mechanical Engineering, \\ Al. Jana Pawła II 37, PL-31864 Cracow, Poland \\ renata.dwornicka@mech.pk.edu.pl \\ ${ }^{3}$ Kielce University of Technology, Faculty of Mechatronics and Mechanical Engineering, \\ Al. 1000-lecia Panstwa Polskiego 7, PL-25314 Kielce, Poland \\ gontar@tu.kielce.pl
}

Key words: ESD coating, laser beam processing, electrodes, properties.

\begin{abstract}
The main objective of the present work was to determine the influence of laser beam processing (LBP) on microstructure, microhardness, surface geometric structure, adhesion tests and tribological properties of coatings deposited on $\mathrm{C} 45$ carbon steel by the electro-spark deposition (ESD) process. The coatings were deposited by means of an EIL-8A. The laser processing was performed with an Nd:YAG, BLS 720 system. The studies were conducted using WC-Cu electrodes produced by the powder metallurgy route. The tests show the lasertreated electro-spark deposited WC-Cu coatings are characterized by higher adhesion and seizure resistance which come at the expense of lower microhardness. In addition, WC-Cu coatings after laser treatment had lower values of parameters of the surface geometric structure. The laser treatment process causes the homogenization of the chemical composition, structure refinement and healing of microcracks and pores of the electro-spark deposited coatings. Laser treated ESD coatings can be applied in sliding friction pairs and as protective coatings.
\end{abstract}

\section{INTRODUCTION}

A number of modern surface processing methods use an energy flux. The examples include electro-spark deposition (ESD) and laser beam processing (LBP). Electro-spark deposition is a cheap high-energy process. The method was first used in the USSR in the 1940s almost simultaneously with the destructive electrical discharge machining. The ESD technique was studied intensively in the 1960s. In the next decade, it was commonly applied to deposit hardmelting materials on selected metals and alloys, mainly steel. Polish scientists became interested in electro-spark alloying of coatings as early as in the 1980s.

Developed in the post-war period, the technology has been frequently modified. Its main advantages are the ability to select precisely the area to be modified, the ability to select the 
coating thickness, which may range from several to several dozen micrometers, good adhesion of a coating to the substrate, and finally, cheap and simple equipment for coating deposition.

The processes of coating formation on metal parts including electro-spark deposition involve mass and energy transport accompanied by chemical, electrochemical and electro-thermal reactions [1]. Today, different electro-spark deposition techniques [2-3] are used; they are suitable for coating formation and surface microgeometry formation $[4,5]$. Coatings produced by electro-spark deposition are applied:

1. to protect new elements,

2. to recover the properties of worn elements.

The electro-spark deposition coating is characterized by a non-etching structure. The surface layer is constituted in environment of local high temperature and high pressure. Electromachining is characterized by [6]:

- $\quad$ shock wave pressure coming from electric spark is $(2-7) \cdot 10^{3} \mathrm{GPa}$,

- temperature reaching $(5-40) \cdot 10^{3}{ }^{\circ} \mathrm{C}$.

Electro-spark deposited coatings have some disadvantages but these can be easily eliminated. One of the methods is laser beam machining; a laser beam is used for surface polishing, surface geometry formation, surface sealing or for homogenizing the chemical composition of the deposited coatings $[7,8]$. One of the advantages of laser-treated electrospark coatings will include: lower roughness, lower porosity, better adhesion to the substrate, higher wear and seizure resistance, higher fatigue strength due to the occurrence of compressive stresses on the surface

electro-spark deposited established based on the

structure, adhesion tests

electro-spark deposited

materials in areas requiring special alloys, for
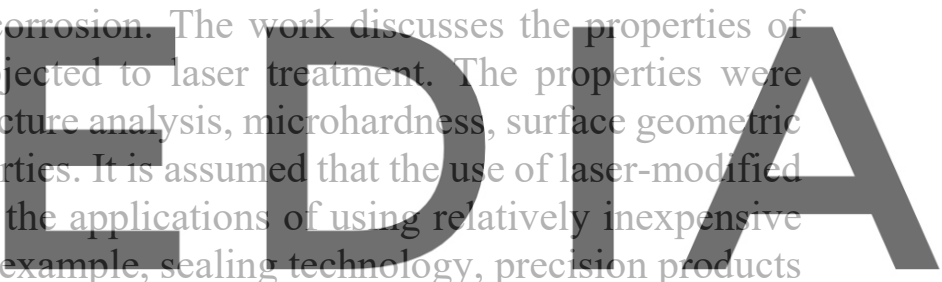

or surfaces in sliding contact.

Register for fheeratilhst providing datasets for the development of analytical methods $[9,10]$, and information for improving techniques to strengthen the resistance of materials in environments that are chemically aggressive $[11,12]$, thermomechanically stressful [13] and exposed to biocorrosion [14-16]. In the industrial area, they can be used to improve the durability of machine parts by strengthening the surface layer $[17,18]$, modifying its resistance $[19,20]$ and performance properties $[21,22]$. The experience gained may be an inspiration in the area of analytical [2325] and organizational [26, 27] methodologies. It can also be useful when designing the structure of specific industrial databases [28, 29], as well as non-contact shaping techniques $[30,31]$.

\section{MATERIALS AND TREATMENT PARAMETERS}

The working electrode (a stationary) was made from $\mathrm{C} 45$ carbon steel. The elemental composition of the steel was as follows (wt.\%): C: $0.42-0.50, \mathrm{Mn}: 0.50-0.80, \mathrm{Si}: 0.10-0.40$, P: 0.04, S: 0.04. An EIL-8A pulse spark generator was used to deposit the coatings on the steel surface. The operating parameters of the generator were determined experimentally: $0.7 \mathrm{~A}, 230$ 
$\mathrm{V}$ and $150 \mu \mathrm{F}$ capacitors. Cylindrical electrodes, $5 \mathrm{~mm}$ in diameter and $10 \mathrm{~mm}$ in height were used. They were produced by means of the impulse-plasma sintering method in a graphite matrix of tungsten carbide (particle diameter $\sim 0,2 \mu \mathrm{m}$ ) and metallic copper (particle diameter $\sim 0.04 \mu \mathrm{m}$ ) nanopowders at a temperature of $950{ }^{\circ} \mathrm{C}$, under a pressure of $40 \mathrm{MPa}$. The nanopowders were mixed in the following proportions: $75 \% \mathrm{WC}$ and $25 \% \mathrm{Cu}, 50 \% \mathrm{WC}$ and $50 \% \mathrm{Cu}, 25 \% \mathrm{WC}$ and $75 \% \mathrm{Cu}$. The following designations were given to the particular electrodes: WC25-Cu75, WC50-Cu50 and WC25-Cu75, Figure 1.

Then, the coatings were treated with an Nd:YAG laser (impulse mode) model BLS 720. The samples with electro-spark deposited coatings were laser-modified using the following parameters: spot diameter $\mathrm{d}=0.7 \mathrm{~mm}$, power $P=60 \mathrm{~W}$, laser beam velocity $v=250 \mathrm{~mm} / \mathrm{min}$, nozzle-workpiece distance $\Delta f=6 \mathrm{~mm}$, pulse duration $t_{i}=0.4 \mathrm{~ms}$, pulse repetition frequency $f$ $=50 \mathrm{~Hz}$, beam shift jump $S=0.4 \mathrm{~mm}$, nitrogen gas shield $Q=25 \mathrm{l} / \mathrm{min}$.

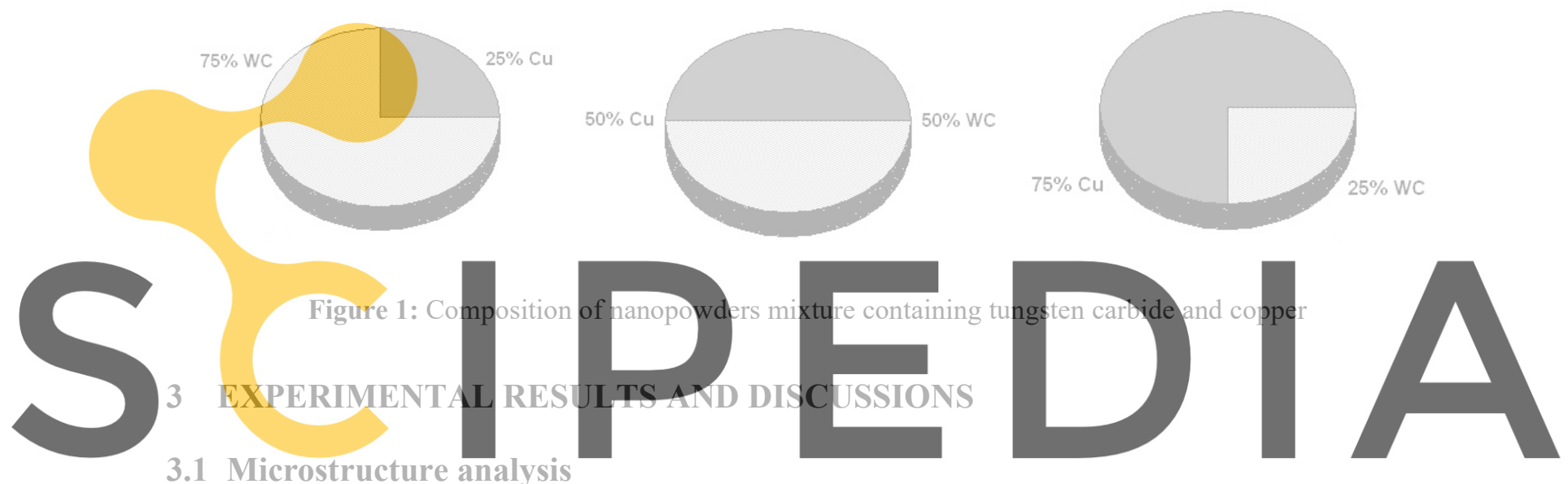

\subsection{Microstructure analysis}

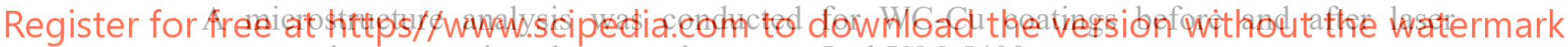
treatment using a scanning electron microscope Joel JSM-5400.

In Figure 2a the microstructure of electro-spark deposited two-layer WC-Cu (WC50-Cu50) coating is presented. The layer thickness is approximately $36-40 \mu \mathrm{m}$, and the range of the heat affected zone (HAZ) inside the (underlying) substrate material is about $20-30 \mu \mathrm{m}$. In the photograph, the boundary line between the two-layer coating and the substrate is clearly visible. There are microcracks running across and along the coating. A linear analysis of the elements (Figure $2 \mathrm{~b}$ ) of the WC-Cu coating shows that the distribution of elements is non-uniform; there are zones with greater concentrations of $\mathrm{W}, \mathrm{Cu}$ and $\mathrm{Fe}$. Analyzing the linear distribution of elements, one can see that the adhesion of the coating to the substrate is of diffusive type.

The melting and solidifying processes during laser treatment resulted in the migration of elements across the coating-substrate interface. Laser radiation caused intensive convective flow of the liquid material in the melt pool and, in consequence, the homogenization of the chemical composition (Figure $3 \mathrm{~b}$ ). It also led to the structure refinement and highly saturated phase crystallization (Figure 3a) due to considerable gradients of temperature and high cooling rates. The technological surface layers, produced by laser alloying, were free from microcracks and pores (an effect of surface sealing), and non-continuities across the coating-substrate interface. No significant change in the chemical composition of the substrate was observed. 
The thickness of the fused two-layer of the WC-Cu coating was in the 40-74 $\mu \mathrm{m}$ range. In the heat affected zone (HAZ), which was 30-45 $\mu \mathrm{m}$ thick (Figure $3 \mathrm{~b}$ ).

\subsection{Measurements of the surface geometric structure}

Surface geometric structure (SGS) is one of the main determinants of its quality. It has a significant influence on many processes occurring in the surface layer. The geometry of the surface is defined as the set of all inequalities resulting from the processes of material consumption. Operational data shows that approximately $90 \%$ of all manufacturing defects originate in the surface from various types of mechanical damage. One of the main disadvantages of the coatings produced by electro-spark deposition is high surface roughness. By reviewing the literature and analyzing the latest developments in this technology, one can notice that the surface generation process involves erosion of the base material and formation of microcraters and ridge by particles leaving the electrode. The surface is regular with rounded microroughness peaks. The effect of the process parameters on the formation of surface roughness has been described in numerous publications. By controlling these parameters, it is possible to obtain surfaces with pre-determined microgeometry. Electro-spark deposition allows for producing surfaces with enhanced roughness called surface relief.
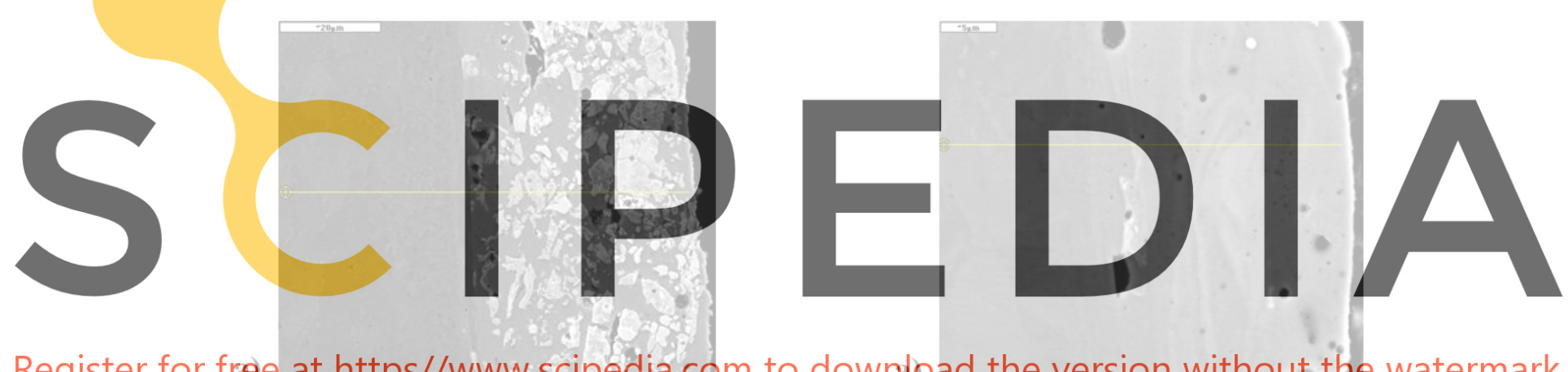

Register for free at https//www.scipedia.com to download the version without the watermark

b)

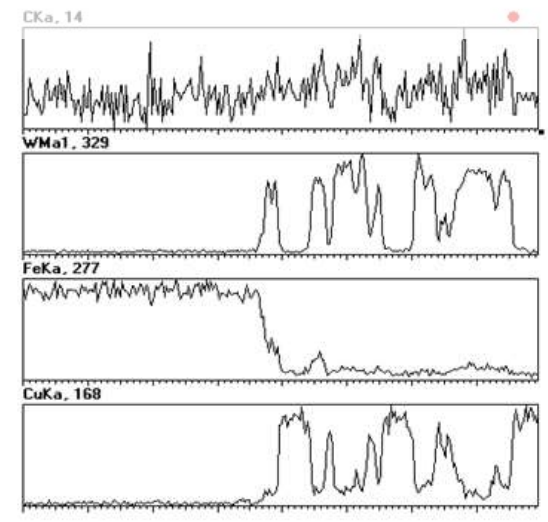

Figure 2: Microstructure (a) and linear distribution of elements (b) in the WC-Cu coating b)

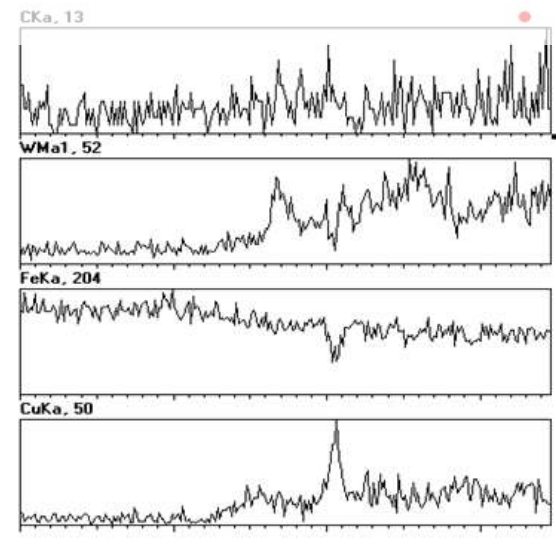

Figure 3: Microstructure (a) and linear distribution of elements (b) in the WC-Cu coating after laser treatment 
The SGS of the WC-Cu coatings was measured at the Laboratory for Measurement of Geometric Quantities of the Kielce University of Technology using a TALYSURF CCI equipment. Three-dimensional surfaces and their analysis using the software TalyMap Platinium allowed us to know thoroughly the geometric structure of the surface tested.

Figure 4 presents an example three- dimensional surface topography measurement of the WC50-Cu50 coatings after and before laser treatment. Table 1 provides major parameters of the surface geometric structure of the examined specimens.

A greater value of the mean arithmetic deviation of surface roughness $S a$, a basic amplitude parameter in the quantitative assessment of the state of the surface under analysis, was recorded for the specimen after the laser treatment. For the specimen before the laser treatment the value of this parameter was higher by almost 5\% . Laser processing caused a slight decrease in the $S a$ parameter, which is very beneficial for surface quality.

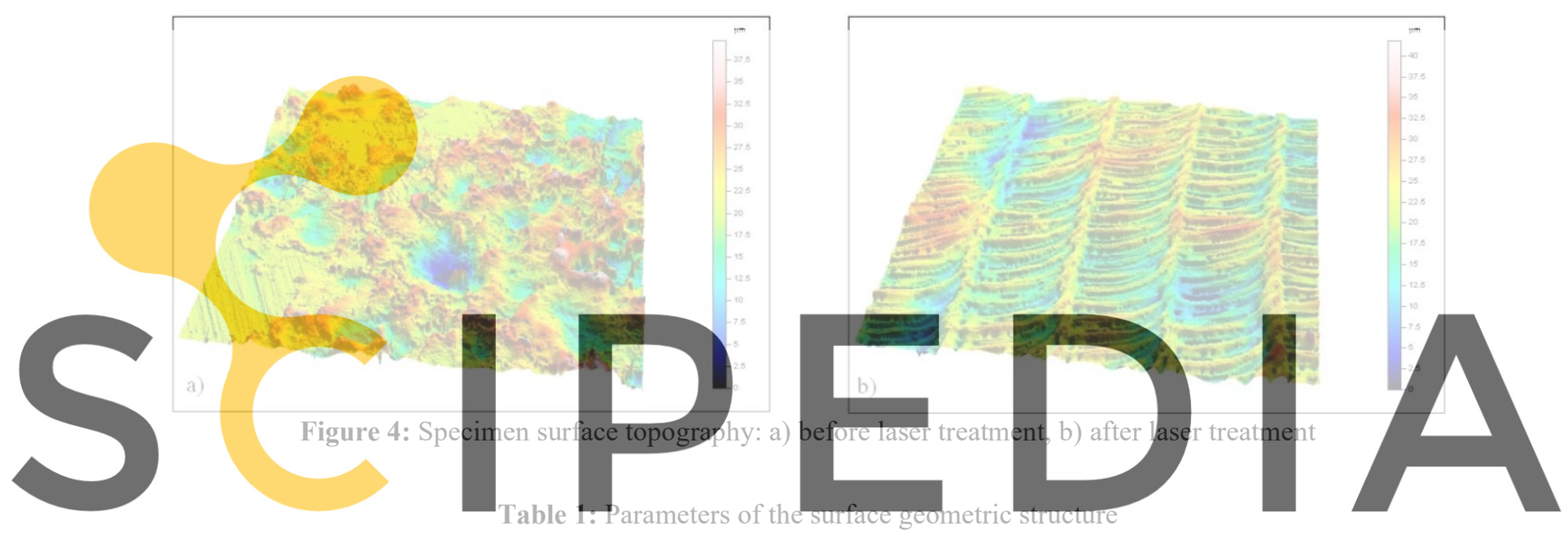

Register for free at https//www.scipedia.com to dowtateag the version without the watermark

parameters WC-Cu WC-Cu+laser

\begin{tabular}{ccc}
$S a(\mu \mathrm{m})$ & 3.98 & 3.80 \\
\hline$S q(\mu \mathrm{m})$ & 5.25 & 4.69 \\
\hline$S s k$ & -0.22 & -0.28 \\
\hline$S k u$ & 3.87 & 2.70 \\
\hline$S p(\mu \mathrm{m})$ & 18.20 & 12.89 \\
\hline$S v(\mu \mathrm{m})$ & 21.52 & 18.96 \\
\hline$S z(\mu \mathrm{m})$ & 39.73 & 31.86 \\
\hline
\end{tabular}

A similar tendency is observed for the root mean square deviation of surface roughness $S q$. Complementary information on how the surface of examined elements is shaped is provided by amplitude parameters, namely the coefficient of skewness (asymmetry) $S k u$ and the coefficient of concentration (kurtosis) Ssk. Those parameters are sensitive to occurrence of local hills or 
valleys, and also defects on the surface. The parameter Ssk has a positive value for both specimens, the value is close to zero for the specimen before treatment, which indicates the symmetrical location of the distribution of ordinates with respect to the mean plane. The values of kurtosis that were obtained are close to $S k u=3$, which indicates that the distribution of ordinates for both specimens is close to normal distribution.

Before laser treatment, the specimen had random isotropic structure $(\mathrm{Iz}=88.52 \%)$, whereas after the treatment, that became a periodic structure, located in the transient area between isotropic and anisotropic structures $(\mathrm{Iz}=55.32 \%)$. That is confirmed by the shape of the autocorrelation function of both surfaces, for the surface before treatment, the shape is circular and symmetrical, whereas for the surface after treatment, it is asymmetrical and elongated.

\subsection{Microhardness and adhesion tests}

The microhardness was determined using the Vickers method (Microtech MX3 tester). The measurements were performed under a load of $0.4 \mathrm{~N}$. The indentations were made in perpendicular microsections in three zones: the white homogeneous difficult-to-etch coating, the heat affected zone (HAZ) and the substrate. The test results for the electro-spark deposited WC-Cu coating before and after laser treatment are shown in diagrams in Figure 5.
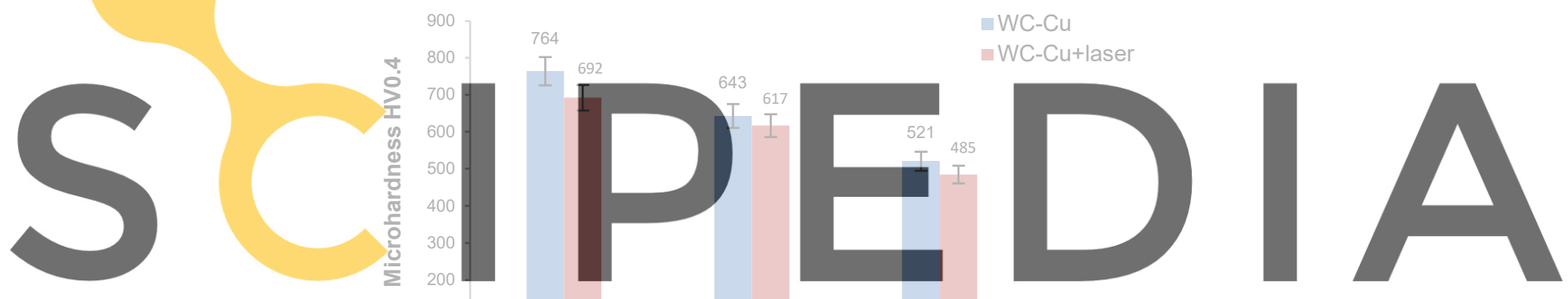

Register for free at https//WWW.scipedia.com to

Coating

Figure 5: Results of the microhardness tests for the WC-Cu coating before and after laser treatment

Electro-spark deposition caused changes in the microhardness of the material. There was a considerable increase in microhardness after depositing the $\mathrm{WC}-\mathrm{Cu}$ coatings. The microhardness of the substrate after electro-spark deposition was on average $278 \mathrm{HV0.4}$; the same value was reported for the substrate before the process. The microhardness of the WC-Cu coatings in the heat affected zone (HAZ) after the electro-spark treatment ranged from $58 \%$ to $63 \%$ and was higher than for the substrate material. The WC75-Cu25 coating had the highest microhardness both before and after laser treatment. The average microhardness of the WC75$\mathrm{Cu} 25$ coating reached $764 \mathrm{HV} 0.4$, and after laser treatment692 HV0.4. After using the WC25$\mathrm{Cu} 75$ electrode, there was a clear decrease of microhardness to the level of $521 \mathrm{HV} 0.4$. It is worth noting that the high content of copper in a WC-Cu coatings leads to a reduction of coating hardness, but at the same time it increases its flexibility, which is essential in improving the strength of some machine parts. The laser treatment of the ESD coatings caused a slight 
decrease in microhardness of both the coatings and heat affected zone. This fall may cause an improvement of their elastic properties, which is of significance during operation under big loads, as is the case of drilling tools in the extractive industry, or press elements in building ceramics. A scratch test was conducted to measure the adhesion of the WC-Cu coatings before and after laser treatment. A CSEM REVETEST scratch tester was used. The measurements were performed at a load increase rate of $39.8 \mathrm{~N} / \mathrm{min}$, a table feed rate of $1 \mathrm{~mm} / \mathrm{min}$ and a scratch length of $5 \mathrm{~mm}$.

The critical force was determined based on the records of changes in the acoustic emission signals and the tangential force as well as on the results of observations with an optical microscope fitted in the REVETEST tester. The values of the critical force were established by comparing the scratches left by the indentor with the responses of acoustic emission signals. Table 2 shows the values of the critical force obtained from three measurements of a given sample, the force mean values and standard deviations.
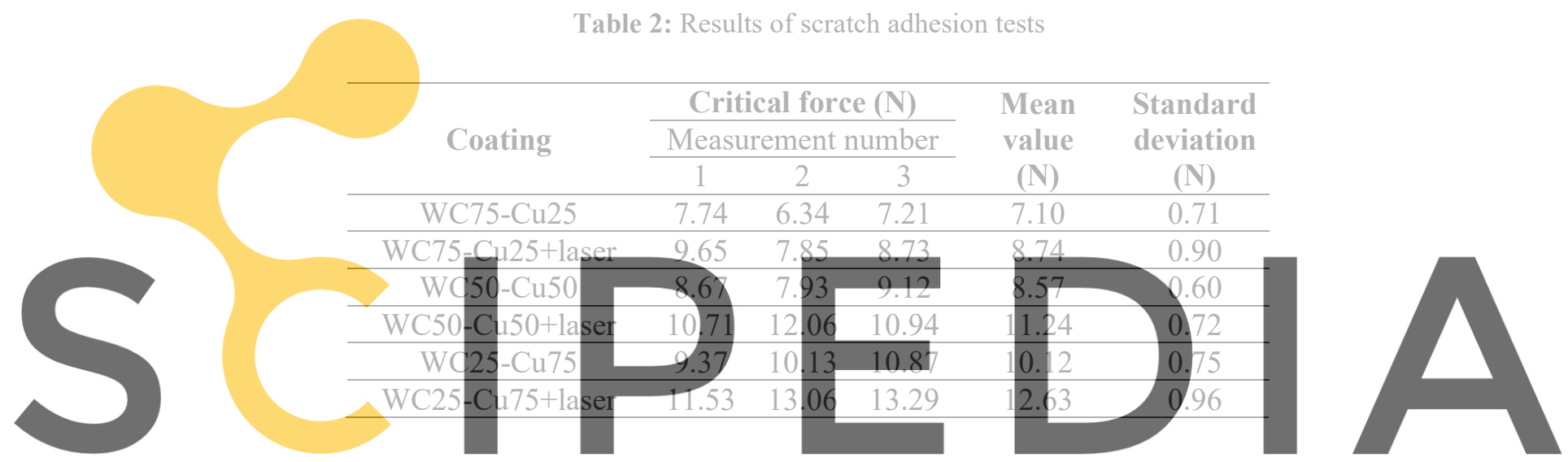

From the obtained data it becomes evident that due to laser treatment it is possible to

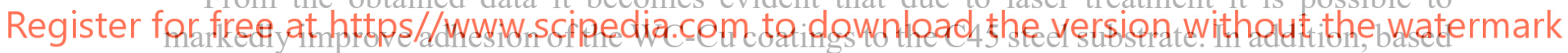

on the results obtained, it can be stated that as the copper content increases, the coating's adhesion to the substrate increases. The $\mathrm{WC} 25-\mathrm{Cu} 75$ coating has the highest adhesion before and after laser processing. The mean value of the critical force of theWC25-Cu75 coating calculated from three measurements was $10.12 \mathrm{~N}$; after laser treatment, it increased to $12.63 \mathrm{~N}$. The laser treatment caused a $20 \%$ improvement in the adhesion of the WC25-Cu 75 coating. In addition, the low scatter of critical stylus loads indicate that the laser treatment presumably eliminate voids present at the coating/substrate interface.

\subsection{Tribological tests}

Seizure resistance tests were carried out using T-09 tribotester, in which the friction pair consisted of a cylinder and two prisms. Prisms with deposited $\mathrm{WC}-\mathrm{Cu}$ coatings and $\mathrm{C} 45$ steel (laser treated and untreated) acted as specimens, whereas a roller of hardened carbon steel, $\phi 6.3$ $\mathrm{mm}$ in diameter, was used as a counter-specimen. In tests, three kinematic pairs were employed to investigate different material options, which made it possible to average experimental results. During the test, paraffin oil bath lubrication was used. Figure 6 presents cumulative information on average values of seizure load for specimens before and after laser treatment. Those indicate 
that laser treatment resulted in an increase in the load that produced seizure both for electrospark deposited coatings and for $\mathrm{C} 45$ steel. The WC25-Cu75 coating has the highest seizure load both before and after laser treatment. The mean value of the seizure load of the WC25$\mathrm{Cu} 75$ coating calculated from five measurements was $6477 \mathrm{~N}$; after laser treatment, it increased to $7563 \mathrm{~N}$. The laser beam machining caused a 14\% improvement in the adhesion of the WC25$\mathrm{Cu} 75$ coating. The higher seizure load of coatings subjected to laser treatment was probably due to their lower porosity related to higher sealing properties. Further details, however, will be established in the next stage of the research. Analyzing Figure 6, it was found that as the copper content increases, the pressure load of the WC-Cu coatings before and after laser treatment increases.

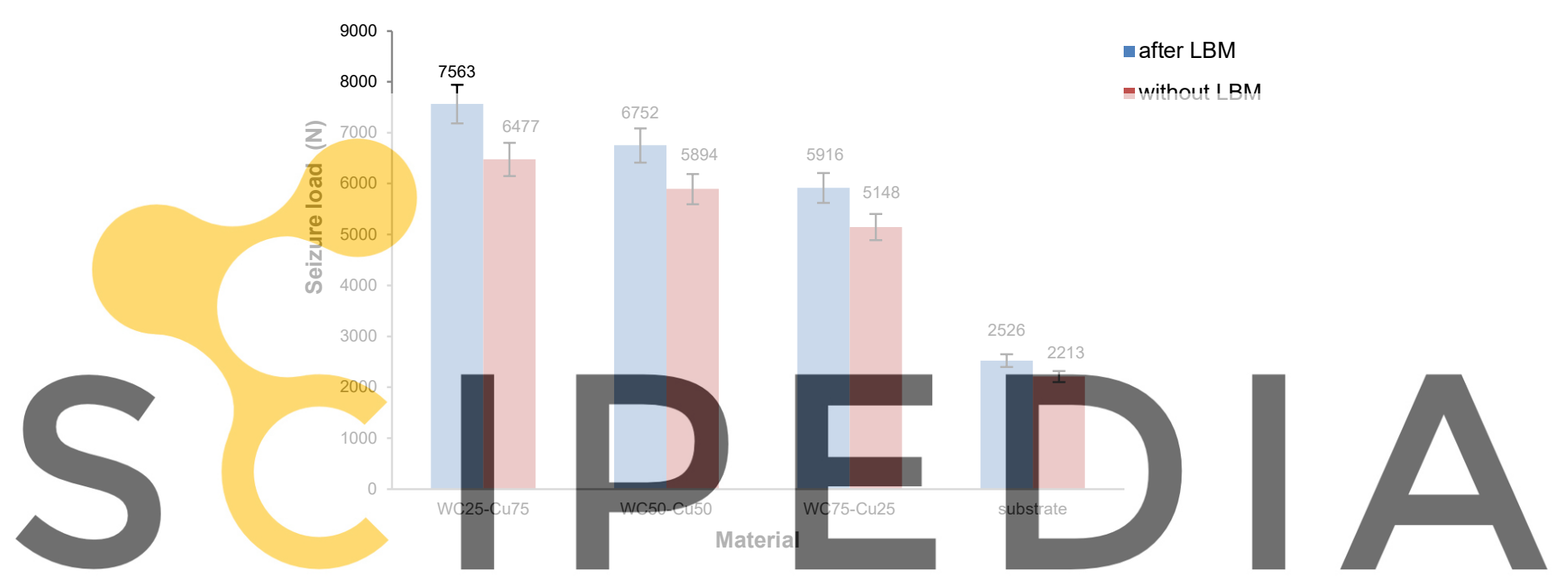

Figure 6: Average values of seizure load

Register for free at https//www.scipedia.com to download the version without the watermark

4. CONCLUSIONS

The following conclusions can be drawn from the analysis and test results.

1. The surface of $\mathrm{C} 45$ carbon steel can be modified by means of electro-spark deposition using WC-Cu electrodes composed of various proportions of its two main constituents.

2. Concentrated laser beams can effectively modifying the state of the outer layer of ESD coatings thus changing their functional properties.

3. Laser irradiation of coatings resulted in the healing of micro-cracks and pores.

4. Parameters of surface geometric structure of the WC50-Cu50 electro-spark coatings have higher values when compared with SGS parameters of coatings after laser treatment.

5. Laser treatment of ESD WC-Cu coatings slightly reduces their microhardness.

6. Laser radiation causes an improvement in the functional properties of the electro-spark deposited WC-Cu coatings, i.e. they exhibit higher resistance to adhesion.

7. Laser processing of WC-Cu coatings increases by approximately $13-14 \%$ the load at which seizure occurs.

8. Further research should involve measurements of internal stresses and investigations into the erosion resistance tests of electro-spark coatings before and after laser beam machining. 


\section{REFERENCES}

[1] Galinov, I.V. and Luban, R.B. Mass transfer trends during electrospark alloying. Surf. Coat. Techn. (1996) 79:9-18.

[2] Chang-bin, T., Dao-xin, L., Zhan, W. and Yang, G. Electro-spark alloying using graphite electrode on titanium alloy surface for biomedical applications. Appl. Surf. Sci. (2011) 257:6364-6371.

[3] Jahan, M.P., Rahman, M. and Wong, Y.S. A review on the convetional and microelectrodischarge machining of tungsten carbide. International Journal of Machine Tools \& Manufacture (2011) 51:837-858.

[4] Radek, N., Sladek, A., Broncek, J., Bilska, I. and Szczotok, A. Electrospark alloying of carbon steel with WC-Co- $\mathrm{Al}_{2} \mathrm{O}_{3}$ : Deposition technique and coating properties. Advanced Materials Research (2014) 874:101-106.

[5] Burkov, A.A. and Pyachin, S.A. Investigation of WC-Co Electrospark Coatings with Various Carbon Contents. Journal of Materials Engineering and Performance (2014) 23:2034-2042

[6] Miernikiewicz, A. The bases of experimental and theoretical in electro discharge machining [in Polish], Technical University of Cracow, Cracow, 1999.

[7] Radek, N. and Konstanty, J. Cermet ESD coatings modified by laser treatment. Archives of Metallurgy and Materials (2012) 57:665-670.

[8] Pietraszek, J., Radek, N. and Bartkowiak, K. Advanced statistical refinement of surface

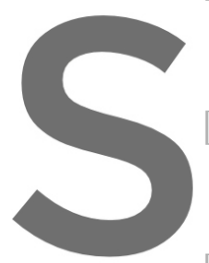
layer's discretization in the case of electro-spark depos
modified by a laser beam. Solid State Phenomena (2013)
Pietraszek, J. and Goroshko, A. The heuristic approach
design, model and valid pre-processing transformation
Materials Research (2014) 874: 145-149.
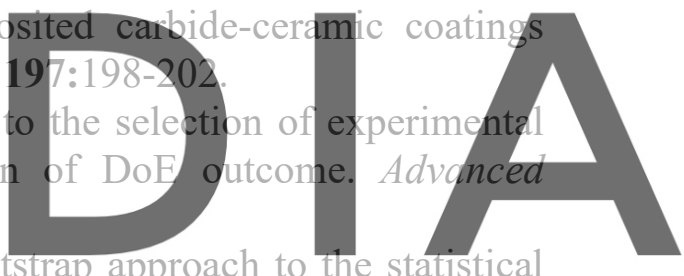

significance of parameters in the fixed effects model.

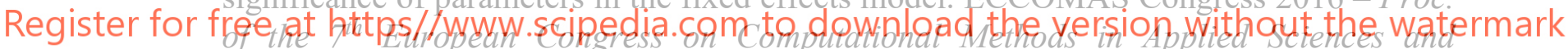
Engineering (2016) 3: 6061-6068.

[11] Skrzypczak-Pietraszek, E., Reiss, K., Żmudzki, P. and Pietraszek, J. Enhanced accumulation of harpagide and 8-O-acetyl-harpagide in Melittis melissophyllum L. agitated shoot cultures analyzed by UPLC-MS/ MS. PLoS ONE (2018) 13(8): art. e0202556.

[12] Skrzypczak-Pietraszek, E., Piska, K. and Pietraszek, J. Enhanced production of the pharmaceutically important polyphenolic compounds in Vitex agnus castus L. shoot cultures by precursor feeding strategy. Engineering in Life Sciences (2018) 18(5): 287-297.

[13] Trzewiczek, K., Szczotok, A. and Gadek-Moszczak, A. Evaluation of the state for the material of the live steam superheater pipe coils of V degree. Advanced Materials Research (2014) 874: 35-42.

[14] Lipinski, T. and Karpisz, D. Effect of animal slurry on carbon structural S235JR steel at 303 K. Engineering for Rural Development (2020) 19: 1482-1487.

[15] Lipinski, T. and Karpisz, D. Effect of animal slurry on carbon structural S235JR steel at 318 K. METAL 2020 - $29^{\text {th }}$ Int. Conf. on Metallurgy and Materials (2020): 643-648. 
[16] Wojnar, L., Gadek-Moszczak, A. and Pietraszek, J. On the role of histomorphometric (stereological) microstructure parameters in the prediction of vertebrae compression strength. Image Analysis and Stereology (2019) 38(1): 63-73.

[17] Korzekwa, J., Gądek-Moszczak, A. and Zubko, M. Influence of the Size of Nanoparticles on the Microstructure of Oxide Coatings. Materials Science (2018) 53(5): 709-716.

[18] Bochenek, D., Niemiec, P., Korzekwa, J., Durtka, B. and Stokłosa, Z. Microstructure and properties of the ferroelectric-ferromagnetic PLZT-ferrite composites. Symmetry (2018) 10(3): art. 59.

[19] Pliszka, I. and Radek, N. Corrosion Resistance of WC-Cu Coatings Produced by Electrospark Deposition. Procedia Engineering (2017) 192: 707-712.

[20] Lipiński, T. and Karpisz, D. Corrosion rate of 1.4152 stainless steel in a hot nitrate acid. METAL 2019 - $28^{\text {th }}$ Int. Conf. on Metallurgy and Materials (2019): 1086-1091.

[21] Dwornicka, R., Radek, N., Krawczyk, M., Osocha, P. and Pobędza, J. The laser textured surfaces of the silicon carbide analyzed with the bootstrapped tribology model. METAL 2017 - 26 th Int. Conf. on Metallurgy and Materials (2017): 1252-1257.

[22] Radek, N., Szczotok, A., Gądek-Moszczak, A., Dwornicka, R., Bronček, J. and Pietraszek, J. The impact of laser processing parameters on the properties of electro-spark deposited coatings. Archives of Metallurgy and Materials (2018) 63(2): 809-816.

[23] Gạdek, A., Kuciel, S., Wojnar, L. and Dziadur, W. Application of computer-aided analysis of an image for assessment of reinforced polymers structures. Polimery/Polymers (2006) 51(3): 206-211

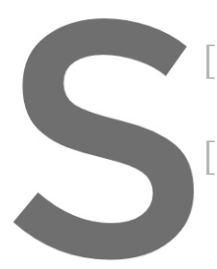

[24] Patek, M., Konat, R., Sladek, A and
welds by the ultrasonic TOFD method.
[25] Gadek-Moszczak, A. and Zmudka, S. D
with polypropylene (pp) matrix and tuf pre
186-191.
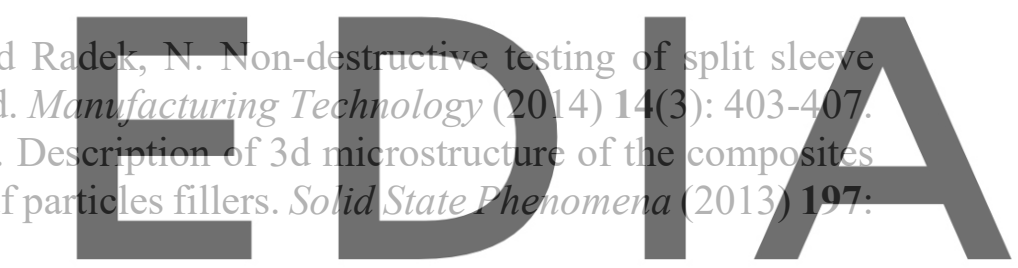

[26] Maszke, A., Dwornicka, R. and Ulewicz, R. Problems in the implementation of the lean

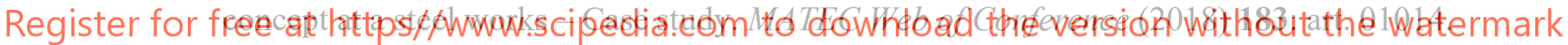

[27] Pacana, A., Czerwińska, K. and Dwornicka, R. Analysis of non-compliance for the cast of the industrial robot basis. METAL 2019 - $28^{\text {th }}$ Int. Conf. on Metallurgy and Materials (2019): 644-650.

[28] Karpisz, D. Design of manufacturing databases. Technical Transactions (2016) 113: 7377.

[29] Pietraszek, J., Sobczyk, A., Skrzypczak-Pietraszek, E. and Kołomycki, M. The fuzzy interpretation of the statistical test for irregular data. Technical Transactions (2016) 113: 119-126.

[30] Radek, N., Kurp, P. and Pietraszek, J. Laser forming of steel tubes. Technical Transactions (2019) 116: 223-229.

[31] Danielewski, H. Laser welding of pipe stubs made from super 304 steel. Numerical simulation and weld properties. Technical Transactions (2019) 116: 167-176. 